\title{
THE INDIVIDUAL DOMINATED EDUCATIONAL ADMINISTRATION SYSTEM
}

by James $\$$. Miles

Many lofty statements are published in university catalogs and annual reports expounding the philosophy, mission or goal of an institution of higher learning. In reality, however, the primary purpose of the university is to provide an environment in which any qualified student can develop individual expression, initiative and intelligence through self-direction and self-evaluation in a program of specialization which will equip him for a vocation of his choice. I should state that in my interpretation the term vocation is expanded beyond the traditional idea of occupation to include training for life, in a more general sense. In any event, this goal must be met in an atmosphere which makes the most effective and efficient use of staff and facilities, allowing faculty the time to engage in stimulating and innovative teaching practices, professional growth, research and public service.

The key to this educational pattern is the individual, the student as well as the professor. Individualization of instruction is not a new concept, but perhaps it is only now in the 70 s that we really have the capability of achieving it. Now it can be reached by combining educational methodology, psychology and learning theory with telecommunications and other forms of technology. This paper will attempt to illustrate this concept by describing a system in which the individual student is allowed to dominate the administrative system in which he pursues his education, thus tailor-making a course of study to his needs.

\section{Background}

For some time I have felt that too great a percentage of the student's time at the university is spent in the "hunting and seeking" processes of securing information or in duplicating efforts in several courses, some of which are not relevant to his ultimate educational goals. Instead it seems that the student should be directing his energies toward the application of information which will have carry-over once he leaves the university. Therefore, the information transfer process must necessarily be made more efficient and expedient and must take place on a one to one ratio in the best possible learning atmosphere. This concept of individualization of instruction is lauded by all but practiced by few due to sheer numbers of students in the 


\section{Dominated System}

university coupled with constraints of traditional teaching and administrative patterns.

With each increment in the student population at Purdue, more and more faculty members have become concerned about teaching methods. This has meant reorganizing the age-old structure of instruction consisting of lectures, laboratories and recitations. Lectures have grown larger and have been given by television. Laboratories have grown alternately longer and shorter, and a few heretics today even suggest that we could do away with them altogether. Recitation groups have changed in all sorts of ways including size, regularity of meetings and purposes. Not only have courses changed, the entire curricula of schools have been similarly modified, changed and rechanged. Still in all, if a student wants three hours of credit at Purdue, he must have a certain number of contact hours with an instructor in order to earn that credit.

The most innovative of our staff have been able to work within this sort of restriction and still allow a great deal of flexibility. The audio-tutorial system utilized by Purdue's Department of Biology, designed by Dr. Sam Postlethwait, is perhaps the prime example of this sort of development. In turn, the audio-tutorial system recently led to the development of minicourses when Dr. Postlethwait decided that a total course, of one or two semesters, was not suitable increment for a learning situation. Therefore, a total course was broken down into small conceptual units called minicourses to be mastered one at a time at the student's individual rate according to a tailor-made plan of study.

The unique idea of the minicourse is that students need not spend time in subsequent courses relearning the same material they have mastered simply because the material is required by a different department under a different course number. For instance, the student who plans to take two semesters of biology, one in botany and one in zoology, could conceivably take a number of minicourses which are common to both, thus avoiding repetition of material. Therefore, the concept of developing courses which fill multiple needs has developed.

Dr. Postlethwait and his colleagues readily recognize that they have gone about as far as they can go under the present constraints of the direct relationship of student-teacher contact hours to credit hours earned by a student. Something must be done to take advantage of the unique capabilities of technology to transfer information and move the responsibility for such information transfer away from the professor, who, although he must maintain responsibility for content, is perhaps at his worst in attempting via lectures and recitations to effectuate such information transfer. 


\section{Mandate for Innovation}

In his "Message on Education Reform, "President Nixon called upon the nation's educators to take a new look at their current blackboard and textbook stage of communication. He said, "There comes a time in any learning process that calls for reassessment and reinforcement. It calls for new directions in our methods of teaching, new understanding of our ways of learning, for a fresh emphasis on our basic research so as to bring behavioral sciences and advanced technology to bear on problems that only appear to be insuperable."1

For some time I, too, have been convinced that some drastic changes needed to be made, but not just in isolated instances as is so often the case in education. Rather, the total concept must be changed so that the potential of technology can be realized to the fullest extent. Technology operates best when incorporated into the systems approach, as evidenced in its adaptation to industry. The belief that the systems approach is also applicable to education underlies the philosophy behind the establishment of a degree program in Instructional System Technology at Chapman College in California in which the "techniques of systems analysis, learning theory and educational technology are combined and utilized to be maximally efficient and effective."2

There are always those who argue that technology must, by its very nature, dehumanize education. However, at a recent conference on "Humanizing Education Through Technology" at Vanderbilt University where I was a participant, quite the contrary was concluded. In one summary of the conference, it was stated that "Technology neither humanizes nor dehumanizes education, however, the way it is used determines whether its impact is humanizing or dehumanizing."3 Consensus further indicated that, "At present, intelligent application of the computer seems the best way to cope with the vast differences among individuals and their various environments in today's society, for it offers learners and teachers alike a broad range of options for learning methods and learning itself and provides opportunities for choices in terms of various needs and occasions." 4

I have taken these pleas for innovation to heart and have attempted to apply what is known about higher education and technology in a somewhat radically new approach which employs the systems concept. In preface to the description of this plan, it should be noted

\footnotetext{
"Richard M. Nixon, "Message on Education Reform," March 3, 1970.

"Chapman College Catalog, Orange California, 1969-70.

"Walter A. Standbury, (Ed.), "Experts Point Way to Better Education Through Technology," Product Engineering, :26, March 2, 1970.

slbid.
} 


\section{Dominated System}

that it has been designed with my immediate concern, Purdue University, in mind. Even on the local level, implementation of this idea will take time ... time for research, development, pilot testing and eventual application of findings. In addition, it must be remembered that, as with any systems approach, continuing study, evaluation and modification play an integral part. With this introduction, the following plan is offered as a possible course of action for individualizing instruction in higher education.

The Individual Dominated Educational Administrative System

A student, in order to learn, needs many things. Among them are help in identifying his academic interests and goals and a course of study aimed at reaching these goals. The course of study should include three elements: (1) the transfer of information, (2) the opportunity and tools for individual study, and (3) the opportunity to apply what has been learned ... through synthesis, extrapolation, etc. The Individual Dominated Educational Administrative System (IDEAS) is aimed at optimizing those opportunities for each individual student within a viable administrative framework.

In capsule form, IDEAS is a plan in which the student plays a greater role in the selection, sequencing and pacing of his educational activities. Initially he would plan his curriculum to meet his individual needs, selecting subjects from a multitude of possible minicourses. Having selected certain content areas, he would acquire information at his own rate using most efficient and effective channels for this "information transfer" element. In most cases the "opportunity to apply" element would involve direct face-to-face instruction with the professor in tutorial and seminar type situations. However, where possible, advantage would be taken of technology for this process too. The "individual study" element which is the most visable of the unique features of IDEAS is described in further detail.

At the fruition of this plan it is altogether feasible that each stu. dent, whether he lived in a dormitory, fraternity house, private rooming house, at home or in an apartment would have a student study position. Each such position would be outfitted with a console consisting of an eleven-inch television monitor and augmented touch-tone pad, a cartridge audio tape recorder and player and an electrostatic coyping device. Each student console would be connected with a switching terminal by two pairs of wires similar to telephone wires. One of the two pairs would be capable of operating up to $10 \mathrm{MHz}$ and would carry the control signals. Each switching terminal would 
be interconnected with the control storage and retrieval location which in turn would be capable of interconnecting with satellite storage and retrieval locations wherever these might exist, on or off campus.

It would also be possible for each student through his touch-tone pad to be able to access (1) the computer which stores his program of action and his record of accomplishments, (2) the computer which can provide direct assistance in finding the materials the student cur. rently needs and information as to where and when integral lectures, seminars or tutorial meetings are available, and (3) a computer which can assist with problem solving. Regardless of its origin, computer, printed page, microform or videotape, all material would appear on the student's television screen. All audio material would be heard on the accompanying speaker and if desired could be recorded on the cassette recorder. Material displayed on the television picture tube could, by means of the electrostatic copier, provide a hard copy for the student's later reference and use.

In order for this concept to become operable, as described above, a systems approach must be incorporated into the educational pattern. Therefore, IDEAS is subdivided into eight operational units which would function in an interdependent manner to insure compatability among all units in the system. The operational units are as follows:

1. Instructional Program. This group, which would numerically be the largest, would include faculty and media specialists who would be responsible for instructional units of work similar to "minicourses" numbering in the thousands which, when properly put together, would make an individually tailored course of study for each student. It should be re-emphasized that the "minicourse" concept would include not only the recapture of information through the use of technology, but computer testing, tutorial meetings, seminars and lectures as needed for each unique learning sequence. By making much of the content of these minicourses replicable, portable and retrievable for use at the student's individual pace, the professor would be released from routine large group instruction for more individual contact with students.

2. Curriculum Counseling. This unit would provide the means by which each student could determine his goals and choose from the thousands of units of instruction developed by the Instruc. tional Program group those units which would allow him to reach these goals. 


\section{Dominated System}

3. Space Utilization. Plans for the utilization of physical space on campus to optimize the availability of space suitable for the individual small group and large group activities prescribed by the Instructional Program section would be handled by this unit. They would manage the physical resources of the university in a way which was compatible with the human resources, the faculty, staff and students.

4. Storage and Retrieval. This unit would optimize the use of all forms of technology (audio tape, videotape, film, slides, photography, microform, etc.) to store and retrieve the materials developed or acquired by the Instructional Program section.

5. Computer Program. This group would be responsible for the programs which would enable storage and recording of (a) the units of work selected by the counselors, (b) the amount and quality of work done by each student, (c) information which would permit validation of programs and tests, and (d) a directory and citation service so that each student could access the materials he needs when he needs them and determine where and when nonstorable related activities are available.

6. Electronics System. This group would be responsible for the switched network which would serve as an interface between the students and the computer and the stored material. This group would also be responsible for the student console de. scribed above.

7. Quality Control. This group would assume the responsibility for maintaining and improving the quality of this educational system. Through research and evaluation they would seek to develop new teaching techniques and methodology as well as new and more effective uses of technology. Their work would be based on the needs of the other groups, and communication would be carried out by the "educational generalist" who would be among the key personnel of this group.

8. Administrative System. This group would be comprised of a body of administrators at all levels of the university. They would review the philosophy of higher education administration in light of the new concepts presented in IDEAS and then would set criteria for making the administration of this system viable. 


\section{Rationale}

The preceding proposal for applying the systems approach to higher education has been built on several premises which need to be tested at the earliest possible time. First of all, it is my belief that such a system would not only be educationally viable, but economically viable as well. In my work as a member of the board of education of a local school district, I have always felt that we must change the currently accepted way of thinking on the part of educators who, when faced with 200 more students, automatically conclude that they need seven or eight more teachers and rooms and at least three more school buses. However, the only possible alternative involves new administrative structures and the use of technology.

Second, I believe that the system can be designed in such a way that it would be replicable on any level and/or scale of educational endeavor. Such a program might well begin in a specific academic department as a testing ground and then be expanded to an entire school within the university and ultimately to the total university. It could also be adapted to junior colleges, elementary and secondary education and continuing education.

\section{Conclusion}

I believe that for total efficiency, the overall concept of such a system must be accepted before any of the individual components can be implemented. The fact that this may call for reorganization of the basic blueprints of existing administrative structural patterns contributes to the uniqueness of IDEAS. However, it also contributes additional resistance to its adoption.

Just as in the case of the NASA program which depends on the support of the nation for its vitality, the technological know-how is available for IDEAS, but without the human element of the system, the total commitment of faculty: and administration, such a plan can never get off the ground. This phenomenon often presents a much more insurmountable problem than even the design of the sophisticated technology required. As C. P. Snow once said, "In a society like ours, academic patterns change more slowly than any others. In my lifetime, in England, they have crystalised rather than loosened. I used to think that it would be about as hard to change, say, the Oxford and Cambridge scholarship examination as to conduct a major revolution. - I now believe that I was over-optimistic."5

SC. P. Snow, "Miasma, Darkness and Torpidity," New Statesman, 42:1587, 1961. ABOUT THE AUTHOR:

Mr. Miles is the Head, Purdue Television Unit at Purdue University. 